Author version of the article accepted in Forest Ecology and Management. The final document is available in Forest Ecology and Management Volume 382, Pages 269-279, December $2016: 10.1016 / j$.foreco.2016.10.020

\title{
The protective effect of forests against rockfalls across the French Alps: influence of forest diversity
}

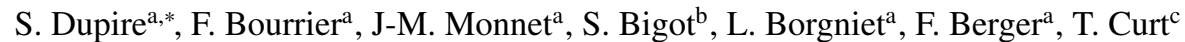 \\ ${ }^{a}$ Université Grenoble Alpes, Irstea, UR EMGR, 2 rue de la Papeterie-BP 76, F-38402 St-Martin-d'Hères, France \\ ${ }^{b}$ Université Grenoble Alpes, IGE, F-38402 Grenoble, France \\ ${ }^{c}$ Irstea, UR EMAX, F-13185 Aix en Provence, France
}

\begin{abstract}
The role of forests in the mitigation of natural hazards has been repeatedly demonstrated. The protective effect of mountain forests against rockfalls has especially been pointed out because it can constitute a natural and cost-effective protection measure in many situations. However, this particular ecosystem service may substantially differ according to the structure and the composition of the forest. Until now, the rockfall protection capability has always been studied at a local scale with only few forest types. Moreover, the comparison of the protective effect of the different forest types studied remains difficult because different methods and indicators were used. For the same reasons, it is not possible to draw conclusions about the influence of biological and structural diversities on the protection capabilities of forests from former works.

The aims of this study were (1) to quantitatively assess the protective effect of forests at the French Alps scale and build a classification based on the protection capability, (2) to compare the protective effect of the different forest types present in the French Alps and (3) to analyse the relations between the protective effect and the forest diversity in terms of stand structure and tree composition. For this purpose, the model Rockyfor3D was used to simulate the propagation of rocks on 3886 different forest plots spread over the whole French Alps. Quantitative indicators characterizing the protective effect of each forest plot were then calculated from the simulation results and used to perform the different analyses.

Our results emphasized the importance of taking into account the length of forest in the maximum slope direction for an accurate assessment of the protective effect. Thus, the minimum length of forest to get a reduction of $99 \%$ of the rockfall hazard was chosen as indicator to compare protective effect between forests. Using this indicator, half of the French Alpine forests presented a high level of protection after a short forested slope $(190 \mathrm{~m})$. A decreasing gradient in the protection capabilities was observed from forest types dominated by broadleaved species to those dominated by conifer species. Moreover, considering an equivalent proportion of conifers, stands dominated by shade-tolerant tree species showed better ability to reduce rockfall hazard. Finally, our study highlighted that a high biodiversity and a structural heterogeneity within the forest have a positive effect on the reduction of rockfalls hazard.
\end{abstract}

Keywords: Mountain forest, Protection capability, Rockfall, Ecosystem services, Biodiversity, Alps

\section{Introduction}

Mountain forests represent a renewable wood resource and provide a wide range of ecosystem services (Briner et al., 2013). Among them, the protection of human beings and infrastructures against natural hazards is essential,

\footnotetext{
${ }^{*}$ Corresponding author at: Irstea, UR EMGR, 2 rue de la Papeterie-BP 76, F-38402 St-Martin-d'Hères, France

Email address: sylvain.dupire@irstea.fr (S. Dupire)
} 
especially in Alpine regions (Bebi et al., 2001). A significant part of the forested area in the Alps provides a natural protection against rockfall (Toe and Berger, 2015; Brang et al., 2001). On forested slopes located below a departure area, it is common to observe scars on trees resulting from one or several rockfall impacts (Favillier et al., 2015). Each impact against a tree reduces the energy of the block which results in a lower velocity or a complete stop (Bertrand et al., 2013; Dorren and Berger, 2006). After a forested slope, both the energy (intensity) and the number of rocks (frequency) threatening human lives and infrastructures are reduced, especially in the case of small volume events ( $\leqslant$ $5 \mathrm{~m}^{3}$ ) (Berger et al., 2002).

Quantifying the protective effect of a forest is of major importance to provide reliable recommendations to forest managers and enrich the argumentation concerning the consideration of forests in local or regional land use management strategies (Notaro and Paletto, 2012). Although early studies were restricted to a qualitative assessment of the protective effect of forests (Wasser and Frehner, 1996; Gsteiger, 1993), the quantitative evaluations have taken a prominent place since the development of reliable modelling tools such as Rockyfor3D (Dorren et al., 2006). Maringer et al. (2016) evaluated the protective capability of beech forests after a fire, Rammer et al. (2015) analysed the effect of forest management on rockfall protection and timber production in a mature spruce stand and Radtke et al. (2014) focused their work on coppice forests of Northern Italy. Fuhr et al. (2015) is the only reference based on many different mountainous uneven aged stands taken across Northern French Alps. Thereby, most of these works limited their analysis to a local scale or to only one forest type. Mountainous forest stands of Abies alba, Picea abies and Fagus sylvatica and more recently coppices have been particularly studied. Although these types of forests are very common, forests are much more diverse at the Alpine scale. Therefore, the current overview of the protective effect of Alpine forests remains incomplete. Even if common trends are noticeable, it is not possible to quantitatively compare the protective effect between the different forest stands as the methods and the indicators used in the previous studies were not standardized.

The aims of this study were (1) to quantitatively assess the protective effect of forests at the French Alps scale and build a classification based on the protection capability, (2) to compare the protective effect of the different forest types present in the French Alps and (3) to analyse the relations between the protection potential and the forest diversity in terms of stand structure and tree composition. For this purpose, we first used the model Rockyfor3D to simulate the propagation of rocks on 3886 different forest plots spread over the whole French Alps from the Mediterranean sea to the Swiss border. Second, quantitative indicators characterizing the protection potential of each forest plot were calculated from the simulation results and used to build the classification based on protection capabilities. The forest plots were then grouped according to their structure and composition in order to compare the protective effect between the different forest types. Finally, the interactions between forest diversity and protection capabilities were analysed.

\section{Material and methods}

\subsection{Source and selection of forest data}

Forest plots were extracted from the permanent sample plots of the French National Forest Inventory (NFI) based on a systematic grid of $1 \mathrm{~km} \times 1 \mathrm{~km}$ covering the complete country. $10 \%$ of the plots are measured each year (approximately 6700 forest plots) resulting in nine fractions from 2005 to 2013. NFI data collection is based on circle plots (Robert et al., 2010) where stand properties and topographic data are assessed in a 25-m radius. On each plot, tree characteristics are inventoried for all trees with a diameter at breast height (DBH) greater than or equal to $7.5 \mathrm{~cm}$.

This study used only the plots with a terrain slope greater than or equal to $20^{\circ}$ and located in the Alpine region (Fig. 1). When the slope is lower than $20^{\circ}$ rocks have a rolling mode of motion and their velocity decreases quickly (Dorren, 2003). Thus, the choice of a $20^{\circ}$ threshold allows considering the protection potential of forests in both transit and deposition zones. This procedure resulted in the selection of 3886 NFI plots measured during the period 2005-2013.

\subsection{Rockfall simulations on NFI plots}

The RockyFor3D software (Dorren, 2015) is a rockfall simulation model taking explicitly into account the protective effect of forests. The trajectories of single, individually falling rocks are simulated in three dimensions (Dorren et al., 2006). The propagation of rocks on a rasterized digital slope is modelled as a succession of sequences of free flights through the air, rebounds on the slope surface, and impacts against trees. 


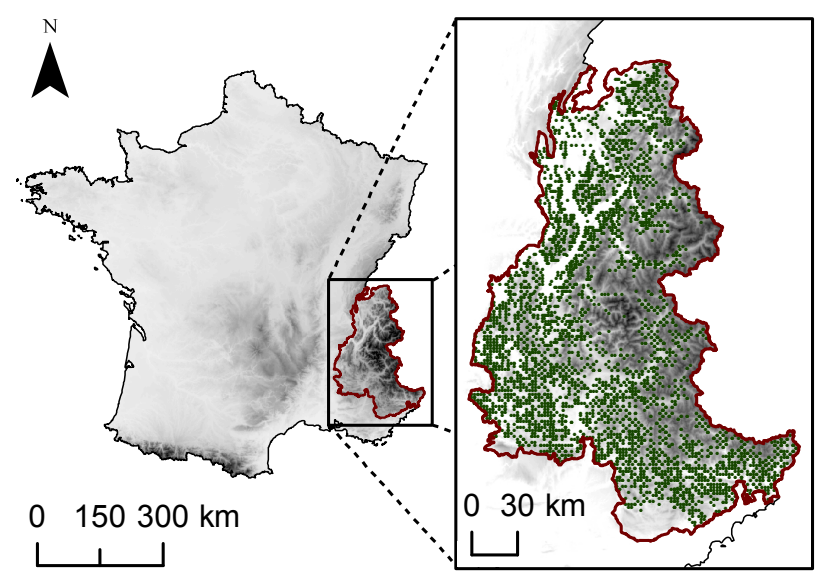

Figure 1: Map of the 3886 selected NFI Alpine plots (green dots). French Alpine region is delimited by the red line.

For each NFI plot, rockfall simulations were run on a virtual slope surface in order to focus on the protective effect of forests. Each virtual digital terrain model had a 2-m resolution, a regular slope $\alpha$ corresponding to the NFI plot slope and a total length $L$ of $2100 \mathrm{~m}$ in the slope direction. Calculation screens were located every 5 meters along the slope surface to register both kinetic energy and number of passing blocks depending on the distance to the release line. The protection potential of the forest was evaluated by comparing the results of simulations with forest and without forest on this virtual slope surface (Fig. 2).

In order to compare and emphasize differences in the protection provided by the different stand structures and compositions, we fixed the surface roughness to $0 \mathrm{~cm}$ and used a medium compact soil (soiltype=3) for all NFI plots (Dorren, 2015). This combination emphasizes the protective effect of the forest which corresponds to the worst plausible scenario with rocks covering a long distance down the slope.

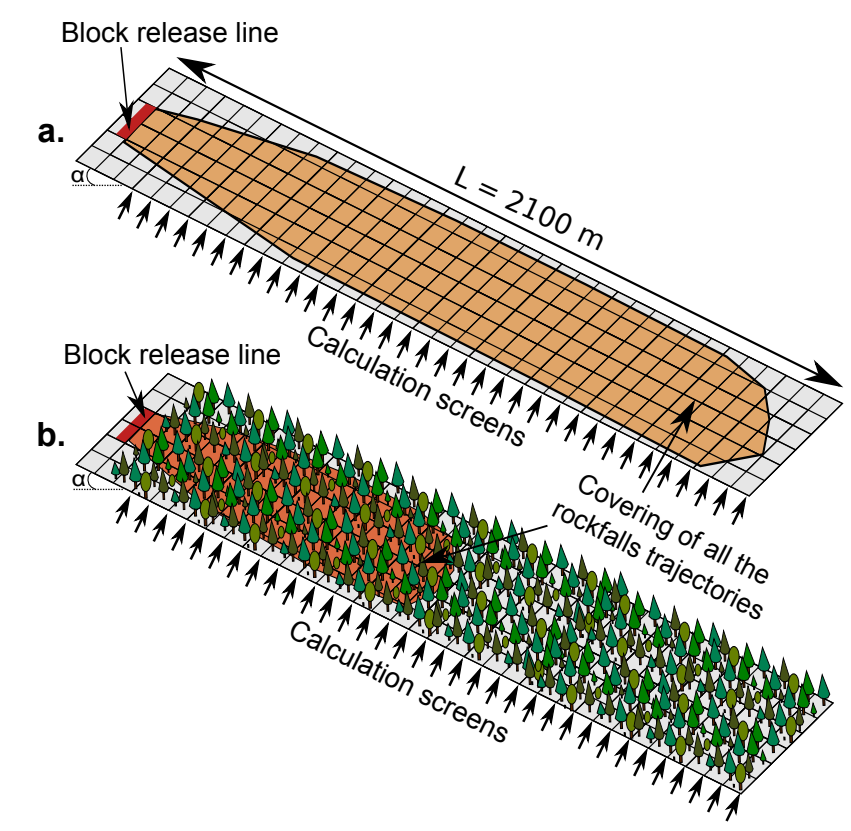

Figure 2: Virtual terrain with uniform slope $\alpha$ and length $L$. Calculation screens are located every $5 \mathrm{~m}$ along the non-forested (a) and forested (b) profiles. 
Integration of forest characteristics in Rockyfor3D is done using the locations and the $D B H$ of all trees on the slope surface. When a rock impacts a tree, its energy is reduced due to both energy transfer and dissipation. Eq. 1 is used to determine the maximum energy reduction of the rock during an impact on a tree depending on the tree species and the $D B H$ :

$$
\text { max. Ered }=\text { Coeff }(\text { species }) \times 38.7 \times D B H^{2.31}
$$

The original version of Rockyfor3D uses only two values for Coeff(species): one for conifers and one for broadleaved species. For the purpose of this study, Rockyfor3D was modified in order to use species values of Coeff(species) (published in Dorren and Berger, 2006) instead of broadleaved / conifer values. For each NFI plot, the forest was generated following two steps. First, the location of the trees in the slope surface were generated following an uniform random distribution of trees coordinates. Second, diameters and species of each tree were attributed following the diameter and species distributions observed on the NFI plot.

Finally, a total of six simulations per NFI plot were tested: one without forest and one with forest for three rock volumes $\{0.5,1,5\} \mathrm{m}^{3}$. All the 23316 (3 rock volumes $\times 2$ (with / without forest) $\times 3886$ plots) simulations were computed on the Grenoble University high performance computing centre (CIMENT).

\subsection{Indicators for the protective effect of forests against rockfall}

Dupire et al. (2016) proposed three indicators to describe and quantify the protective effect of forests against rockfall. These indicators can be estimated with three forest characteristics: the basal area and the mean diameter of all trees with a DBH greater than or equal to $7.5 \mathrm{~cm}$ and the forested length in the maximum slope direction from the release area $(L)$. Their main advantage is to be independent of the slope.

In this paper, we mainly focused on the overall rockfall protection index (ORPI) which integrates both the proportion of stopped rocks (frequency) and the total energy reduction of the rocks due to the presence of forest (intensity). This indicator is calculated as shown in Eq. 2:

$$
\operatorname{ORPI}(L)=100 \times\left(1-\frac{\sum_{i=1}^{n f o r} E_{i}(L)}{\sum_{k=1}^{\text {nbare }} E_{k}(L)}\right)
$$

On the same slope surface, $O R P I(L)$ compares the sum of the energies of all the blocks that reached the distance $L$ from the release line according to two configurations: (1) a forested slope surface $\left(\sum_{i=1}^{n f o r} E_{i}(L)\right)$ and (2) a bare slope surface $\left(\sum_{k=1}^{n b a r e} E_{k}(L)\right)$. nfor and nbare correspond to the number of blocks that reached the distance $L$ for the configurations (1) and (2), respectively.

Two other indicators were proposed by Dupire et al. (2016). The first one traduces the ability of forests to stop some of the falling blocks. It is called the barrier effect index (BARI) which quantifies the reduction in term of frequency of the falling blocks. The second indicator quantifies the reduction of the maximum energy of the blocks and is called the maximum intensity reduction index $(M I R I)$. In this study, these two indicators were only used for illustrative purpose.

The three indicators range from 0 (no protective effect) to 100 (high protective effect). They were calculated on each NFI plot and for each rock volume. This resulted on $11658(3 \times 3886)$ simulations where values of the three indicators are known for $L \in[50-2100] \mathrm{m}$.

\subsection{Definition of classes for the rockfall protection capabilities of Alpine forests}

In the Cartesian coordinate system defined by the basal area as abscissa and the mean DBH as ordinate, the three indicators evolve following a clockwise motion and straight lines can be computed to discriminate plots located above (or under) any ORPI value as shown in Fig. 3 (Dupire et al., 2016).

The classification proposed in this study follows three steps. First, for each NFI plot the minimum forest length $L_{99}$ required to get an ORPI value greater than or equal to 99 (99\% of the overall rockfall hazard reduced) were picked out from the results of Rockyfor3D simulations. Second, a k-medoids clustering was applied to define the optimal number of classes $k$ that best separates the NFI plots according to their values of $L_{99}$ (i.e. to their protection capabilities). Finally, the equations of the straight lines separating the $k$ classes were computed. 

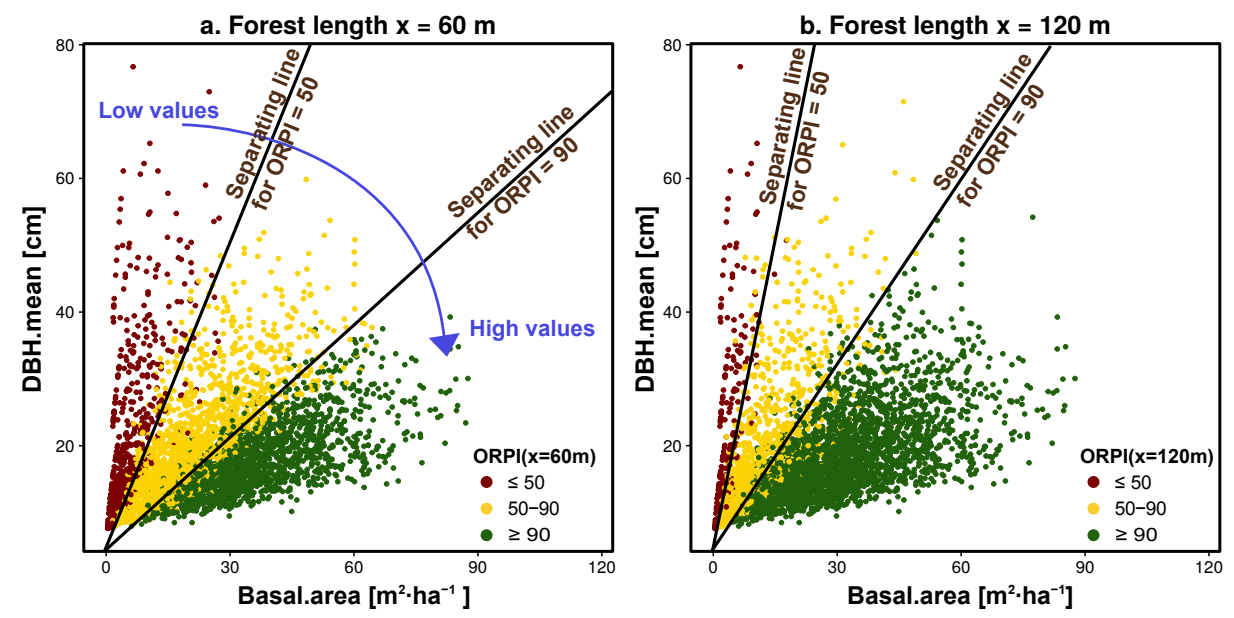

Figure 3: Illustration of the clockwise motion of $O R P I$ values for a rock volume of $1 \mathrm{~m}^{3}$ at forest lengths $x=60 \mathrm{~m}$ (a.) and $x=120 \mathrm{~m}$ (b.). Points are coloured according to $\operatorname{ORPI}(x)$. The separating lines between plots were $\mathrm{ORPI}(\mathrm{x})<90$ (or 50$)$ and plots were $\mathrm{ORPI}(\mathrm{x}) \geq 90$ (or 50$)$ are shown. (Figure adapted from Dupire et al., 2016)

\subsection{1. $k$-medoids clustering}

The k-medoids clustering is an adaptation of the k-means clustering. Rather than calculating the mean of the items in each cluster, a representative item, or medoid, is chosen for each cluster at each iteration. k-medoids is more robust to noise and outliers than k-means (Reynolds et al., 2006). Indeed, for each cluster, medoids are calculated by finding object within the cluster that minimizes a sum of pairwise dissimilarities instead of a sum of squared Euclidean distances. The k-medoids clustering can be summarized as follow: (1) choose $k$ objects at random to be the initial cluster medoids, (2) assign each object to the cluster associated with the closest medoid, (3) recalculate the positions of the k-medoids and (4) repeat steps 2 and 3 until the medoids become fixed.

In this study, the aim of the k-medoids clustering is to find the optimal number of clusters $(k)$ that allows the best partitioning of the NFI plots into $k$ classes of rockfall protection capability. The PAM (Partitioning Around Medoids) algorithm of the cluster R-package (Reynolds et al., 2006; Kaufman and Rousseeuw, 1990) was applied on the dataset defined by three characteristics of the 3886 NFI plots: the basal area, the mean $D B H$ and the minimum forest length $L_{99}$ required to get ORPI $\geqslant 99$ for a rock of $1 \mathrm{~m}^{3}$.

Three criteria were used to determine the optimal number of clusters with $k \in[2-10]$. First, the gap statistic (Tibshirani et al., 2001) was calculated for each value of $k$. This method returns the optimal number of clusters defined as the smallest $k$ such as $\operatorname{gap}(k)$ is not more than one standard error away from the first local maximum. Second, the average silhouette width $s_{i}$ was calculated for each $k$. Only $k$ satisfying $s_{i}>0.5$ (partition qualified as "reasonable structure") were kept. Finally, the smallest number of NFI plots by cluster was checked and only $k$ such as each cluster was composed with at least $5 \%$ of the NFI plots (i.e. 200 plots) were selected.

\subsubsection{Computation of the separating lines between the $k$ classes of protection}

The k-medoids clustering was used to obtain the optimal number of clusters $k$ as well as objective threshold values for the minimum forest length required to get ORPI $\geqslant 99\left(L_{99}\right)$ for all NFI plots of each cluster. To evaluate the protection potential of a forest, the equations of the straight lines corresponding to each threshold value of $L_{99}$ were computed as shown in Eq. 3:

$$
D B H=\text { slope } \times \text { Basal.area }+ \text { intercept }
$$

Finally, Kruskal-Wallis tests were performed on the NFI plots classified using the separating lines method for the three following stand characteristics: basal area, mean DBH and stem density. The tests were followed by a pairwise comparisons between protection classes using the Dwass-Steel-Critchlow-Fligner post-hoc procedure (Hollander et al., 2013) only if the Kruskal-Wallis indicated significant differences in the means. 


\subsubsection{Validation of the classification method}

Each NFI plot was assigned to one of the $k$ protection classes according to its own coordinates and the locations of the different separating lines in the reference system defined by the basal area as abscissa and the mean DBH as ordinate. To evaluate the quality of this classification, the predicted protection classes obtained with a rock volume of $1 \mathrm{~m}^{3}$ were compared to the effective $L_{99}$ values for the three rock volumes $\{0.5,1,5\} \mathrm{m}^{3}$.

Four statistics were used to evaluate the accuracy (Congalton, 1991): (1) the total accuracy which gives the proportion of correctly classified plots, (2) the user accuracy which return the commission error, (3) the producer accuracy which measures the omission error and (4) the Intraclass Correlation Coefficient (ICC) (Bartko, 1966) which reflects the difference between actual agreement and the agreement expected by chance. The agreement is generally qualified as good from 0.6 to 0.8 and very good when it is greater than 0.8 . A value of 1 indicates a perfect agreement.

The last step to evaluate the accuracy of this classification was to check that the values taken by $L_{99}$ and $\operatorname{ORPI}\left(L=L_{99}\right)$ were correctly distributed between the $k$ classes defined earlier.

\subsection{Analysis of the protective effect against rockfalls by forest types}

All the 3886 Alpine NFI plots were divided into 4 groups based on the forest composition and the stand characteristics as shown in Fig. 4.

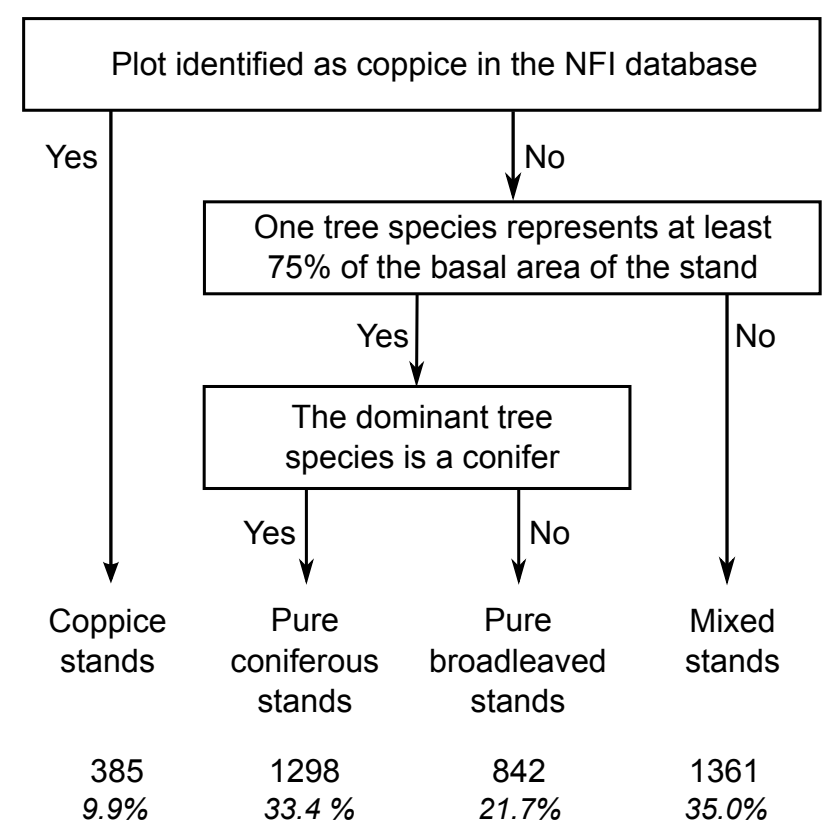

Figure 4: Decision tree for the classification of the NFI plots into four groups. The number and proportion of plots are displayed below each group.

These four groups were used as basis for the forest typology of French Alps. Each group was split into different forest types according to the dominant species present on the NFI plot. The distributions of the $L_{99}$ values of each forest types were then compared.

\subsection{Forest biodiversity and rockfall protection}

The influence of forest composition on the protective effect of Alpine forests against rockfalls was investigated at two levels. First, a comparison of the rockfall protection capacities between pure and mixed stands was performed using Wilcoxon rank sum tests (Hollander et al., 2013; Wilcoxon, 1945).

Second, three indexes were calculated on each NFI plot: two measuring biological diversity and one measuring structural diversity. The two first indexes are the tree species richness and the tree species evenness, both measuring the tree species biodiversity (Gray Stirling, 2001). The richness gives the number of tree species present on each 
plot while the evenness (Pielou, 1966) measures the relative abundance (number of stems) and the distribution of the different tree species. The third index is the Gini coefficient that measures the inequality of a variable within a set of observation (Jacob Weiner, 1984; Gini, 1921). Gini coefficient ranges from 0 (perfect equality) to 1 (high inequality). In this study, it was calculated on each NFI plot according to the DBH distribution, therefore it returns an index of the structural diversity of the stand. The distributions of these three indexes within the $k$ rockfall protection classes were analysed and Kruskal-Wallis tests were performed to test for significant difference in the means. Finally, the tests were followed by a pair-wise comparisons between protection classes using the Dwass-Steel-Critchlow-Fligner post-hoc procedure in order to verify if lower forest diversities are observed in forests with lower protection capabilities.

\section{Results}

\section{1. $k$-medoids clustering}

Table 1 shows the values of three different statistics to choose the optimal number of clusters $k$. All of them converged to an optimal number $k=6$. It corresponded to (1) the highest number with an average silhouette width $\left(s_{i}\right)$ greater than $0.5,(2)$ the optimal number according to the gap statistic and (3) the highest number with at least $200 \mathrm{NFI}$ plots by cluster. Values for $k \in[8-10]$ are not shown as they did not fulfil the requirements for both average silhouette width and minimum number of plots by cluster.

\begin{tabular}{lllllll}
\cline { 2 - 7 } & \multicolumn{6}{c}{ Number of clusters $k$} \\
\cline { 2 - 7 } & 2 & 3 & 4 & 5 & $\mathbf{6}$ & 7 \\
\hline Average silhouette width & 0.87 & 0.78 & 0.62 & 0.61 & $\mathbf{0 . 6 0}$ & 0.51 \\
Gap statistic & 0.63 & 0.70 & 0.76 & 0.80 & $\mathbf{0 . 8 4}$ & 0.84 \\
Minimum number of plots by cluster & 403 & 343 & 322 & 310 & $\mathbf{3 0 3}$ & 134 \\
\hline
\end{tabular}

Table 1: Statistics of the k-medoids clustering (PAM) according to the number of clusters $k$.

Using $k=6$, the ranges of values for the minimum forest lengths $L_{99}$ to get ORPI $\geq 99$ are shown for each cluster (i.e. each protection class) in Table 2.

\begin{tabular}{lll}
\hline Protection class & $L_{99}$ range $[\mathrm{m}]$ & Number of plots \\
\hline Class 1 & $L_{99} \leq 110$ & 1037 plots \\
Class 2 & $110<L_{99} \leq 190$ & 1184 plots \\
Class 3 & $190<L_{99} \leq 320$ & 652 plots \\
Class 4 & $320<L_{99} \leq 600$ & 362 plots \\
Class 5 & $600<L_{99} \leq 2100$ & 373 plots \\
Class 6 & $L_{99}>2100$ & 278 plots \\
\hline
\end{tabular}

Table 2: Ranges of $L_{99}$ values and numbers of NFI plots for the six protection classes defined with the k-medoids clustering.

\subsection{Equations of the partition lines into 6 classes of rockfall protection}

Fig. 5 shows the partition of the NFI plots into 6 classes with the separating lines method for an intermediate rock volume of $1 \mathrm{~m}^{3}$. The number of NFI plots and the distributions of the basal area, mean DBH and stem density are also displayed. Equations of the different separating lines are shown in Table 3.

Kruskal-Wallis tests indicated significant differences in the means for the three stand characteristics displayed in Fig. 5. The pair-wise comparisons between protection classes returned significant differences between all classes when considering the basal area or the stem density. However, only the protection class 6 significantly differed from the others when considering the mean DBH.

\subsection{Validation of the partition into 6 classes of rockfall protection}

The statistics to assess the quality of the partition of NFI plots with the 5 separating lines are shown in Table 4 . Even if the partition lines were calibrated for a $1 \mathrm{~m}^{3}$ rock volume, the partition give similar statistics for smaller rock volumes $\left(0.5 \mathrm{~m}^{3}\right)$. However, regardless the statistic, the quality of partition is lower for largest rock volume $\left(5 \mathrm{~m}^{3}\right)$. Total, user and producer accuracies oscillate around 0.7 which shows a good correlation between observed $L_{99}$ and 


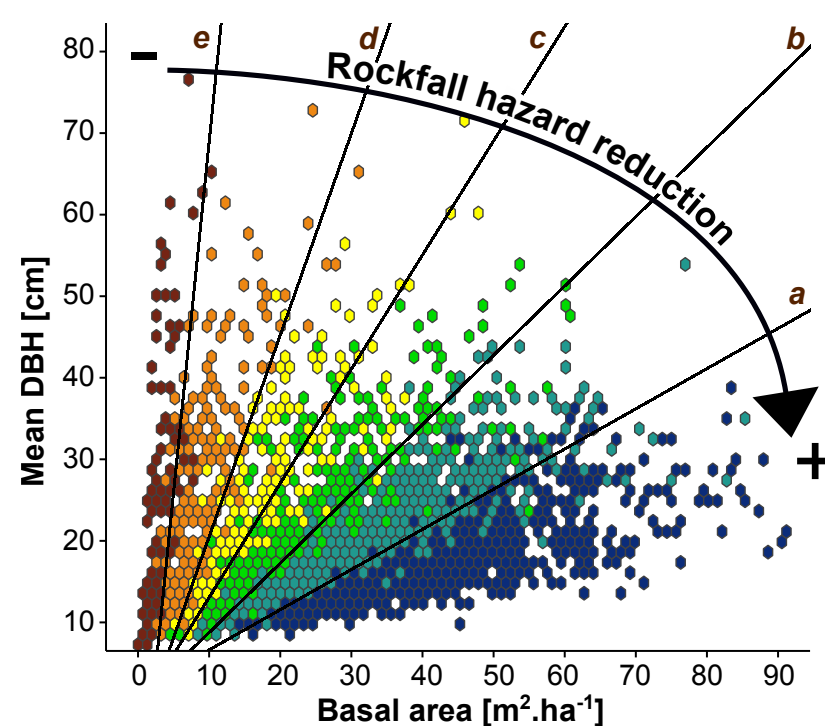

Protection class: L $_{99}$ range [m]
$1: \leq 110$

4: $320-600$
2: $110-190$

5: $600-2100$
3: $190-320$

6: > 2100
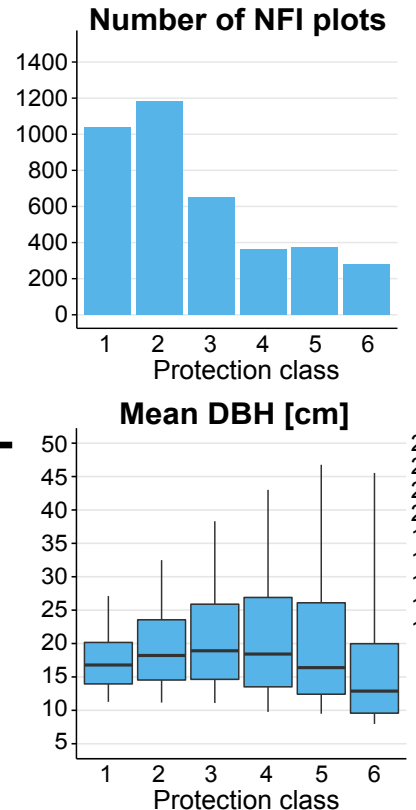

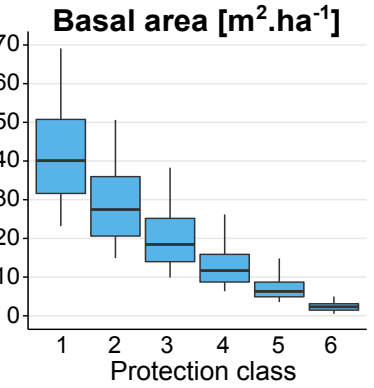

Stem density [ha ${ }^{-1}$ ]

Figure 5: Classification with the separating lines method (Dupire et al., 2016) with a rock volume of $1 \mathrm{~m}^{3}$. For a better visualization, NFI plots were grouped by hexagonal pixels, the colour represents the average value of the $L_{99}$ of all the NFI plots contained in the pixel. The number of NFI plots per class and the distribution of the basal area, mean DBH and stem density are also shown.

\begin{tabular}{lll}
\hline \multicolumn{2}{l}{ Separating line between classes } & \multicolumn{1}{c}{ Equations } \\
\hline$a: 1-2$ & at $L_{99}=110 \mathrm{~m}$ & $y=0.4927 \cdot x+1.70$ \\
$b: 2-3$ & at $L_{99}=190 \mathrm{~m}$ & $y=0.8499 \cdot x+0.26$ \\
$c: 3-4$ & at $L_{99}=320 \mathrm{~m}$ & $y=1.3999 \cdot x-0.94$ \\
$d: 4-5$ & at $L_{99}=600 \mathrm{~m}$ & $y=2.4731 \cdot x-4.24$ \\
$e: 5-6$ & at $L_{99}=2100 \mathrm{~m}$ & $y=8.5885 \cdot x-16.96$ \\
\hline
\end{tabular}

Table 3: Equations of the 5 lines separating the 6 classes of protection for a rock volume of $1 \mathrm{~m}^{3}$.

predicted protection classes. User and producer accuracies are close which indicates a similar level of commission and omission errors. The values taken by the intraclass correlation coefficient (ICC) indicate a very good agreement between observed $L_{99}$ and predicted protection classes.

\begin{tabular}{llll} 
& \multicolumn{3}{c}{ Rock volume $\left[\mathrm{m}^{3}\right]$} \\
& 0.5 & $\mathbf{1}$ & 5 \\
\hline Total accuracy & 0.74 & $\mathbf{0 . 7 5}$ & 0.62 \\
User accuracy & 0.71 & $\mathbf{0 . 7 5}$ & 0.62 \\
Producer accuracy & 0.73 & $\mathbf{0 . 7 5}$ & 0.58 \\
ICC & 0.91 & $\mathbf{0 . 9 1}$ & 0.89 \\
\hline
\end{tabular}

Table 4: Evaluation of the quality of the partition with the separating lines.

Fig. 6 shows the distribution of the minimum forest length $L_{99}$ observed for the three indicators presented in this study (see section 2.3). Predicted protection classes obtained with the separating lines for a $1 \mathrm{~m}^{3}$ rock (abscissa) are compared to $L_{99}$ observed in Rockyfor3D simulations (representing, by extension, the observed protection classes). About $75 \%$ of the $L_{99}$ values observed for $O R P I$ are distributed between the right protection classes for the rock volumes 0.5 and $1 \mathrm{~m}^{3}$. For $5 \mathrm{~m}^{3}, L_{99}$ are well classified only for the three best protection classes. BARI (rockfall frequency reduction) and MIRI (rockfall maximum intensity reduction) are shown for informative purpose. We can observe a shift to one classes up for BARI and to 2 classes up for MIRI. The same trends were observed for the 
distributions of the values taken by the three indicators according to the rock volume and the predicted protection classes (see Fig. A.1). Regardless the rock volume, ORPI values are always above 95 which indicates that $95 \%$ of the overall rockfall hazard is reduced after a forest length of $L_{99}$. BARI values are slightly shifted down compared to $O R P I$, they are always above 90 for both rock volumes 0.5 and $1 \mathrm{~m}^{3}$ but take a wider range of values for biggest rock volume. MIRI values are significantly lower. However, we can notice that, regardless the rock volume, the maximum intensity is reduced by at least $50 \%$ and even more when considering large rock volume on the best protection classes.

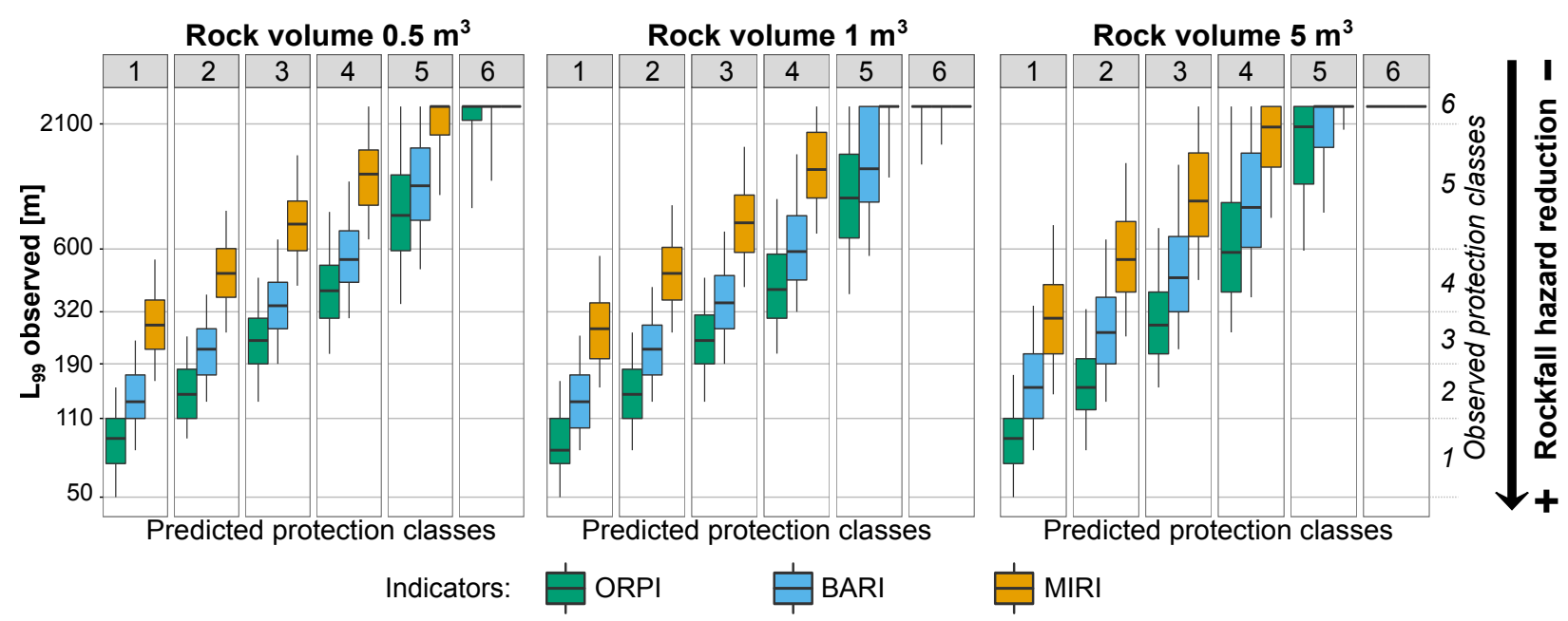

Figure 6: Distribution of the minimum forest length $L_{99}$ observed in Rockyfor3D simulations for the three indicators of rockfall hazard reduction according to the 6 classes of protection predicted with the separating lines obtained for a $1 \mathrm{~m}^{3}$ rock. Ordinate axis has a logarithmic scale.

\subsection{Distribution of the forest types into the 6 classes of rockfall protection}

Fig. 7 shows the distribution of the minimum forest length $L_{99}$ required to get an ORPI value greater than or equal to 99 according to the different forest types. At the French Alps scale, coppices dominated by Fagus sylvatica and deciduous Quercus sp. present the best rockfall hazard reduction. They are followed by pure stands of Castanea sativa and Fagus sylvatica and mixed stand of Abies/Picea/Fagus. The lowest rockfall reduction rates are observed in pure coniferous stands of Pinus sp. and Larix decidua. More in details (Fig. A.2), in pure coniferous stands, forest types dominated by Abies alba and Picea abies present higher protective capabilities than forest types dominated by Pinus sp. or Larix decidua. In broadleaved stands (pure or coppice), forest types dominated by Fagus sylvatica present higher protective capabilities than those dominated by Quercus sp. Finally, in mixed stands, this hierarchy between species is also observed and forest types dominated by Abies alba, Picea Abies and Fagus sylvatica present higher protective capabilities than those dominated by Pinus sp. and Quercus sp..

\subsection{Comparison of the protective effect against rockfall of pure and mixed stand}

The comparison of the protection potential of pure stands and mixed stands dominated by the same species was performed using a Wilcoxon rank sum test. For each test, the alternative hypothesis "mixed stand have a higher protective effect than pure stand" was also tested. Results are shown in Table 5. In most case, mixed forests presented a higher protection capability, it was always verified when comparing pure coniferous stands with mixed stands dominated by the same species. However, no improvement of the protection capabilities is observed when two coniferous species are mixed or when comparing pure broadleaved stands with mixed stands.

A comparison of the proportion of NFI plots per forest group with a high protective effects according to the forest length in the slope direction is displayed in Fig. 8. Considering all NFI plots in each group independently of the forest type confirmed the hierarchy observed previously. Coppices had the highest protection capabilities followed by pure broadleaved stands and mixed stands. Pure coniferous stands came last. 


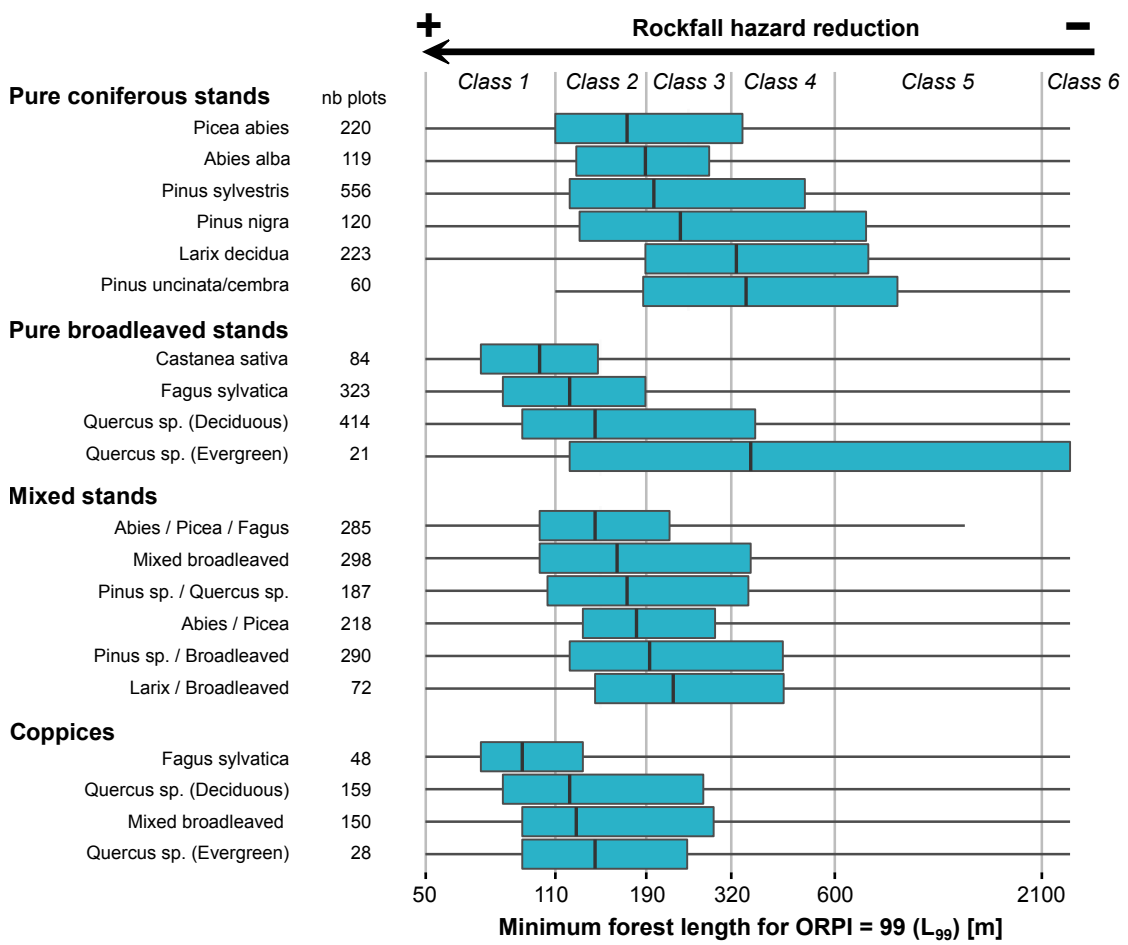

Figure 7: Distribution of the minimum forest length $L_{99}$ observed for each forest type of the French Alps (logarithmic scale). The number of NFI plots by forest type is also given.

Mixed stand $>$ Pure stand

\begin{tabular}{lll}
\hline Pure stand & Mixed stand & Wilcoxon p-value \\
\hline Picea abies & Picea/Abies / Fagus & $<10^{-3}$ \\
Abies alba & Picea / Abies / Fagus & $<10^{-3}$ \\
Larix decidua & Larix/ Broadleaved sp. & 0.004 \\
Pinus sylvestris & Pinus sp. / Broadleaved sp. & 0.045 \\
Pinus sylvestris & Pinus sp. / Quercus sp. & 0.014 \\
Pinus nigra & Pinus sp. / Broadleaved sp. & 0.050 \\
Pinus nigra & Pinus sp. / Quercus sp. & 0.009 \\
Pinus uncinata/cembra & Pinus sp. / Broadleaved sp. & $<10^{-3}$ \\
Pinus uncinata/cembra & Pinus sp. / Quercus sp. & $<10^{-3}$ \\
\hline & & \\
Mixed stand $\leq$ Pure stand & Wilcoxon p-value \\
\hline Pure stand & Mixed stand & 0.628 \\
\hline Picea abies & Picea/Abies & 0.403 \\
Abies alba & Picea/Abies & 0.999 \\
Fagus sylvatica & Picea/Abies / Fagus & 0.957 \\
Quercus sp. & Pinus sp. / Quercus sp. \\
\hline
\end{tabular}

Table 5: Results of the Wilcoxon Rank Sum test performed to compare pure stands against mixed stands. The alternative hypothesis tested is that mixed stands have a higher protective effect.

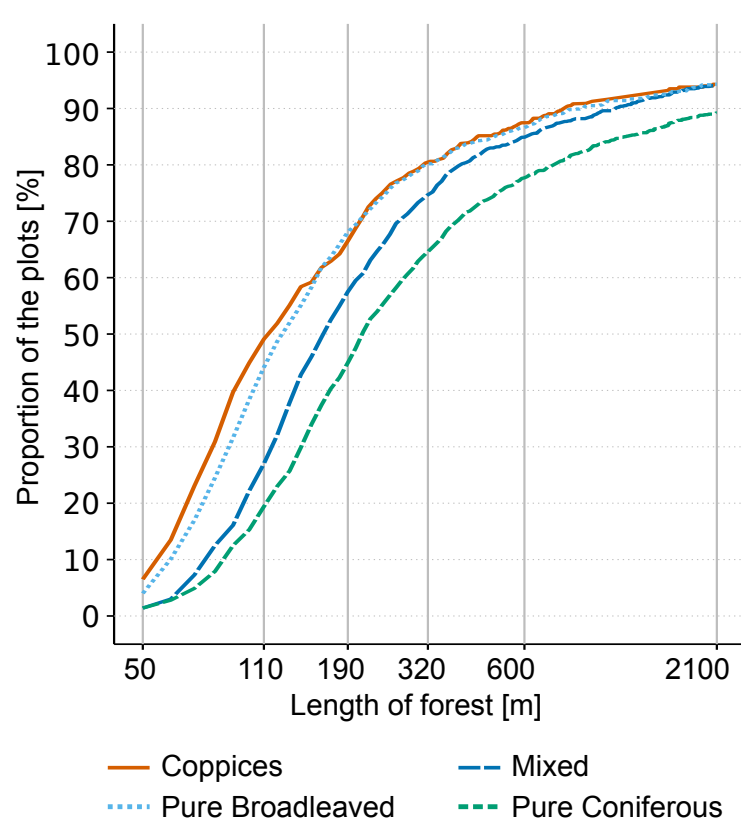

Figure 8: Proportion of NFI plots by forest stand group such as $\operatorname{ORPI}(x) \geq 99$ for $x \in[50-2100] \mathrm{m}$ and for a rock of $1 \mathrm{~m}^{3}$. Abscissa has a logarithmic scale. 


\subsection{Influence of tree species biodiversity and structural diversity on rockfall protection capability}

Fig. 9 shows the distribution of NFI plots per protection class according to the Gini coefficient based on DBH and the tree species richness and evenness. For the three indexes, the highest values correspond to the highest diversity. Regardless of the index, the protection classes offering the best rockfall hazard reduction present the highest stand diversity.

Kruskal-Wallis tests indicated significant differences in the means for the three diversity indexes. The pair-wise comparisons between protection classes returned significant differences between all classes regarding the tree species richness and evenness. In addition, the pair-wise comparison underlined a gradual degradation of biological diversity indexes ranging from the highest classes of protection to the lowest. However, for the Gini coefficient based on DBH, this trend was only observed for the last four protection classes (from 3 to 6), the result of pairwise-comparisons between the first two classes (1 and 2) being not significant.
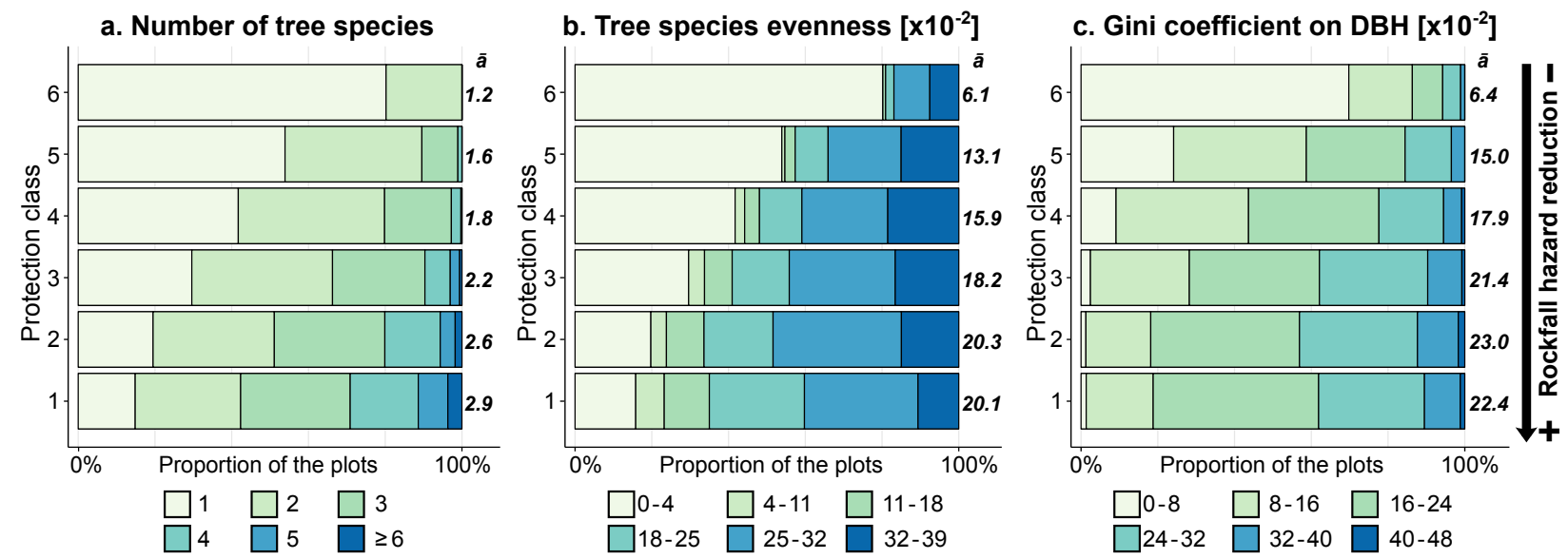

Figure 9: Distribution of the tree species richness (a), evenness (b) and Gini coefficient based on DBH (c) according to the six protection classes. For each protection class, the average value of each diversity indicator $(\bar{a})$ is given.

\section{Discussion and conclusion}

Until recently, the evaluation of the protective effect of forests against rockfall was mainly assessed qualitatively. With the growing capabilities of numerical tools, efforts toward a quantitative assessment become more and more relevant and valuable (Trappmann et al., 2014; Straub and Schubert, 2008; Corominas et al., 2005). This study worked in this direction by proposing a quantitative assessment of the protective effect of forests against rockfalls using only two forest parameters (basal area and mean DBH) taken from field inventories and the overall rockfall protection index (ORPI) derived from simulations results. Using ORPI presents the advantage of combining both aspects of risk analysis, i.e. the frequency and the intensity of the hazard. Therefore, it brings added value to previous studies with quantitative assessments mainly focused on the reduction of the frequency (Jancke et al., 2009; Berger and Dorren, 2007; Stoffel et al., 2006). The three parameters exposed before were used to evaluate the minimum length of forest to reach $99 \%$ of rockfall hazard reduction $\left(L_{99}\right)$. $L_{99}$ was finally adopted as main indicator to evaluate the protective effect of forests at the Alpine scale and to compare protection capabilities of the different forest types of the study area.

\subsection{Protective effect of forests at the French Alps scale}

The 3886 different forests studied in this paper are spread over the whole French Alps from the Mediterranean sea to the Swiss border. The quantitative assessment of the protective effect of forests had never been studied before on such forest diversity, whether in terms of forest structures or compositions. Therefore, this work provided a complete 
and reliable overview of the protection capabilities of the French Alpine forest which may be generalized to similar European mountain forests.

According to our results, half of the French Alpine forests presented a high ability to reduce rockfall hazard (see Table 2 and Fig. 5). Indeed, $27 \%$ of the forests were classified in the best protection class meaning that $99 \%$ of the hazard was reduced after $110 \mathrm{~m}$ of forest. This proportion grew up to $57 \%$ after $190 \mathrm{~m}$ of forest (i.e. considering protection classes 1 and 2). These forests with a high protection capability were defined by an important growing stock (Fig. 5) with high stem density ( $>800$ stems.ha ${ }^{-1}$ ) and high basal area $\left(>30 \mathrm{~m}^{2} \cdot \mathrm{ha}^{-1}\right)$. These results agreed with real size experiments which showed that, for effective protection, a large number of trees is more important than having thick trees only (Dorren et al., 2006, 2005). On the other hand, at the French Alps scale, there were still about $17 \%$ of the forests ranked in the two last protection classes meaning that $600 \mathrm{~m}$ of forested slope was not enough to reach a reduction of $99 \%$ of the rockfall hazard. Those forests were characterized by a stem density lower than 300 stems.ha ${ }^{-1}$ and a basal area lower than $15 \mathrm{~m}^{2} \cdot \mathrm{ha}^{-1}$ (Fig. 5) which mainly corresponded to sub-alpine stands of Pinus sp. or Larix decidua and open forests of evergreen Quercus sp. (Fig. 7).

\subsection{Protective effect according to structural and biological forest diversities}

The comparison of the protection potentials of the main forest types present in the French Alps returned interesting trends, particularly concerning the influence of the dominant tree species on the protection capabilities (Fig. 7). First, considering an equivalent proportion of conifers, the protection potential of the different forest types seemed independent of the Coeff(species) attributed to each tree species to determinate the maximum energy a tree can reduce (Eq. 1). For instance, for coniferous stands, Pinus sp. have a Coeff(species) of 1.12 which is higher than Abies alba and Picea abies: 1.0 and 0.9 respectively (Dorren and Berger, 2006). Despite that, the protection capability of coniferous stands dominated by Pinus sp. was lower. The same trend was observed for broadleaved stands between Quercus sp. (2.18) and Fagus sylvatica (1.67). This finding underlined that stands dominated by shade-tolerant tree species such as Fagus sylvatica, Abies alba and Picea abies had a better protection potential than stands dominated by light-demanding species such as Quercus sp., Pinus sp. or Larix decidua. Shade-tolerant species are known to be more competitive (Kunstler et al., 2012) and more susceptible to grow under high forest densities (Götmark and Kiffer, 2014; Rohner et al., 2012) which are favourable to reduce the rockfall hazard. This point agreed the recent findings of Toe (2016) and Dupire et al. (2016) who showed that the structure (stem density, DBH and basal area) and composition of the forest stand were prevailing compared to the mechanical properties of the tree species.

Second, the analysis shown in Fig. 8 highlighted a decreasing gradient in the protection capabilities from forest types dominated by broadleaved species to those dominated by conifer species. This can be marginally explained by the values of Coeff(species) which ranged from 1.13 to 2.74 for broadleaved and from 0.66 to 1.13 for conifers. The main explanation is certainly in the historical silviculture of broadleaved forests in the Alps which were traditionally managed as coppice to produce firewood for the winter (Radtke et al., 2014). Coppices are generally characterized by a high density of small stems which is particularly efficient for rockfall protection as shown in our results and already mentioned in previous works (Toe, 2016; Jancke et al., 2009). Nowadays, many former coppice forests are undergoing natural succession or are progressively being converted into high forests. Thus, many of the plots classified as "pure broadleaved stands" are in the transition from coppice to high forest and present a high density of stems which explains their high capability in reducing rockfall hazard. Concerning coniferous forests, stands dominated by Abies alba and Picea abies are mostly uneven-aged with a high structural heterogeneity and a relatively high density, resulting in an interesting protective effect. Conversely, forests dominated by Pinus nigra (and to a lesser extend by Pinus sylvestris) are mostly plantations aged from 60 to 160 years (Burylo et al., 2011). Their structure is therefore homogeneous with a stem density that decreases with time resulting in a low protective effect. Finally, our study showed that the presence of other tree species (especially broadleaved) in any pure coniferous stand went along with a significantly higher ability to reduce rockfall hazard.

More generally, according to our results (Fig. 9), it seems worthwhile to promote heterogeneity and diversity within the forest stand in order to enhance its protective effect. Thus, higher biodiversity indexes and structural heterogeneity index were observed in the most protective forests. Different studies carried out on European forests have shown that increasing species richness promotes growth ability and higher diversity in shade tolerance (Morin et al., 2011; Vilà et al., 2007), especially in broadleaved forests. This trend was also observed in our results with broadleaved forests and mixed forests showing higher growing stock resources than pure conifer stands resulting in an indirect positive effect on their protection capabilities (Table 5). 


\subsection{Implications for forest management}

Several lessons can be learned from this study to improve the management of mountain forests. First, our study emphasized the influence of the length of the forested slope in the assessment of the protective effect of a forest. Currently, there are few mentions of the forest length in silviculture guides in Switzerland (Dorren et al., 2015), France (Ancelin et al., 2006) or Italy (Berretti et al., 2006) except that it should be greater than $250 \mathrm{~m}$ to ensure a significant protective effect. Although this value seemed correct for the most dense forests analysed in this study, our results demonstrated that $250 \mathrm{~m}$ are not always enough to ensure a high level of protection. Moreover, these guides give recommendations in terms of stem density and tree diameter to reach an optimal protective effect in the long term which are meant to be the best trade-off between stand regeneration and protection capability. However, considering these optimal values without taking into account the forest length can sometimes lead to nonsenses. For example, on long forested slopes, keeping a dense forest is not as important as on short slopes and a lower stand density could make the regeneration process easier without consequences on the protective effect against rockfall. Nevertheless, if the rockfall frequency is very high or the slope very steep the rate of broken trees after block impacts may increase significantly (Favillier et al., 2015). Therefore, in these configurations the stem density has to stay high enough to maintain a high protective effect even if the length of forest is important. This point has to be especially considered for forest types dominated by tree species presenting a moderate resilience to numerous rock impacts, i.e. tree species with thin bark such as Fagus sylvatica (Trappmann and Stoffel, 2013).

Second, our results showed that a high protective effect is compatible with a richer diversity within the forest stands, both in terms of biological diversity and structural heterogeneity. This result extends the findings of Fuhr et al. (2015) who demonstrated that the high biodiversity observed in mature forests with a lot of deadwood can counterbalance a low forest density and provide a satisfactory protection against rockfalls. It also complements the arguments in favour of preserving or even increasing the diversity within forests in order to provide a wide range of ecosystem services (Turner et al., 2007). In this way, a direct recommendation to forest managers would be to promote secondary tree species in their forests and particularly the shade-tolerant species. This is especially important in pure coniferous stands which are the most common forest ecosystems in the Alps.

\subsection{Limitations and perspectives}

The simulations on regular virtual slope and the settings of Rockyfor3D adopted in this study aimed at emphasizing potential differences between forests while keeping a ground description that is common in mountain forests. The combination of regular slope, soil type and soil roughness chosen leads to a maximum propagation of rocks down the slope which corresponds to the worst plausible scenario. Thereby, our results are conservative, meaning that, on rougher ground, on softer soil or on concave slopes, values of $L_{99}$ are likely to be shorter (Monnet et al., 2016). Furthermore, information about the spatial structure of forests was unavailable in NFI database which forced us to use a random generation of the stand. This point can lead to a marginal overestimation of the protective effect of forest as discussed in Dupire et al. (2016). The same stands characteristics and slope properties were used on a $2100 \mathrm{~m}$ slope. This produces homogeneous forest stand and slope surface on the entire mountainside which can be unrealistic. Indeed, in mountain areas, forest structures and species compositions evolve following a gradient of altitude. This choice was made to emphasize differences between forest structures and composition while controlling non-forest parameters.

The classification into 6 classes proposed in this study allows a fast evaluation of the protective effect of any Alpine forest with only the basal area and the mean DBH. This method returns a reliable but qualitative assessment of the protective effect of the forest which may be insufficient for a complete analysis with a monetary valuation of this particular ecosystem service. Providing an accurate quantitative assessment of the protective effect against rockfalls of any Alpine forest constitutes an interesting perspective to go further in this work. This could be done using a $k$-Nearest Neighbours algorithm ( $k$-NN) (Mansuy et al., 2014; Eskelson et al., 2009) on the dataset containing the results of the rockfall simulations on the 3886 forests analysed in this paper. With such a tool, a forest manager could enter the mean DBH and basal area of a forest and instantly get the different quantitative indicators (see section 2.3) observed in the most similar forests of the dataset.

Finally, the results of this study could be used in order to identify the forested slopes with a high level of rockfall risk at a large scale. The protection forests could be first identified with a geographic information system by a simple method locating forests situated between rock release areas and human issues (Toe and Berger, 2015). Then, a 
rockfall risk level could be given according to the length of forest and the forest types present on the slope. If spatial information about DBH and basal area are known (for example on areas covered with Lidar), the process could even lead to a spatial quantitative assessment of the protective effect of forest against rockfall at a very large scale.

\section{Funding}

This work was supported by the French Ministry of Ecology, Sustainable Development and Energy [grant $\mathrm{n}^{\circ}$ 2101527657]; the ANR SAMCO [grant $\mathrm{n}^{\circ}$ ANR-12-SENV-0004]; and the Labex OSUG@2020 [grant $\mathrm{n}^{\circ}$ ANR10 LABX56]. Most of the computations presented in this paper were performed using the CIMENT infrastructure supported by the Rhône-Alpes region [grant n ${ }^{\circ}$ CPER07_13 CIRA].

\section{References}

Ancelin, P., Barthelon, C., Berger, F., Cardew, M., Chauvin, C., Courbaud, B., Descroix, L., Dorren, L. K. A., Fay, J., Gaudry, P., Gauquelin, X., Genin, J., Joud, D., Loho, P., Mermin, E., Plancheron, F., Prochasson, A., Rey, F., Rubeaud, D., Wlerick, L., 2006. Guide des sylvicultures de montagne: Alpes du Nord françaises. Cemagref, CRPF Rhône-Alpes, ONF.

Bartko, J. J., 1966. The intraclass correlation coefficient as a measure of reliability. Psychological Reports 19 (1), 3-11.

Bebi, P., Kienast, F., Schönenberger, W., 2001. Assessing structures in mountain forests as a basis for investigating the forests' dynamics and protective function. Forest Ecology and Management 145 (1-2), 3-14.

Berger, F., Dorren, L. K. A., 2007. Principles of the tool Rockfor.net for quantifying the rockfall hazard below a protection forest. Schweizerische Zeitschrift für Forstwesen 158 (6), 157-165.

Berger, F., Quetel, C., Dorren, L. K. A., 2002. Forest: a natural protection mean against rockfalls, but with which efficiency. In: International Congress Interpraevent. pp. 815-826.

Berretti, R., Caffo, L., Camerano, P., De Ferrari, F., Domaine, A., Dotta, A., Gottero, F., Haudeman, J.-C., Letey, C. Meloni, F., Motta, F., Terzuolo, P.-G., 2006. Selvicoltura nelle foreste di protezione. Compagnia delle Foreste.

Bertrand, D., Bourrier, F., Olmedo, I., Brun, M., Berger, F., Limam, A., 2013. Experimental and numerical dynamic analysis of a live tree stem impacted by a Charpy pendulum. International Journal of Solids and Structures 50 (10), 1689-1698.

Brang, P., Schönenberger, W., Ott, E., Gardner, B., 2001. Forests as protection from natural hazards. In: Evans, J. (Ed.), The Forests Handbook. Vol. 2. Blackwell Science Ltd., Oxford, pp. 53-81.

Briner, S., Huber, R., Bebi, P., Elkin, C., Schmatz, D. R., Grêt-Regamey, A., 2013. Trade-Offs between Ecosystem Services in a Mountain Region. Ecology and Society 18 (3).

Burylo, M., Hudek, C., Rey, F., 2011. Soil reinforcement by the roots of six dominant species on eroded mountainous marly slopes (southern alps, france). \{CATENA 84 (1-2), $70-78$.

Congalton, R. G., Jul. 1991. A review of assessing the accuracy of classifications of remotely sensed data. Remote Sensing of Environment 37 (1), $35-46$.

Corominas, J., Copons, R., Moya, J., Vilaplana, J. M., Altimir, J., Amigó, J., 2005. Quantitative assessment of the residual risk in a rockfall protected area. Landslides 2 (4), 343-357.

Dorren, L. K. A., 2003. A review of rockfall mechanics and modelling approaches. Progress in Physical Geography 27 (1), $69-87$.

Dorren, L. K. A., 2015. Rockyfor3D (v5.2) revealed - Transparent description of the complete 3D rockfall model. ecorisQ URL www. ecorisq.org

Dorren, L. K. A., Berger, F., 2006. Stem breakage of trees and energy dissipation during rockfall impacts. Tree Physiology 26 (1), 63-71.

Dorren, L. K. A., Berger, F., Frehner, M., Huber, M., Kühne, K., Métral, R., Sandri, A., Schwitter, R., Thormann, J.-J., Wasser, B., 2015. Das neue nais-anforderungsprofil steinschlag. Schweizerische Zeitschrift fur Forstwesen 166 (1), 16-23.

Dorren, L. K. A., Berger, F., le Hir, C., Mermin, E., Tardif, P., 2005. Mechanisms, effects and management implications of rockfall in forests. Forest Ecology and Management 215 (1-3), 183-195.

Dorren, L. K. A., Berger, F., Putters, U. S., 2006. Real-size experiments and 3-D simulation of rockfall on forested and non-forested slopes. Natural Hazards and Earth System Sciences 6 (1), 145-153.

Dupire, S., Bourrier, F., Monnet, J.-M., Bigot, S., Borgniet, L., Berger, F., Curt, T., 2016. Novel quantitative indicators to characterize the protective effect of mountain forests against rockfall. Ecological Indicators 67, 98-107.

Eskelson, B. N. I., Temesgen, H., Lemay, V., Barrett, T. M., Crookston, N. L., Hudak, A. T., 2009. The roles of nearest neighbor methods in imputing missing data in forest inventory and monitoring databases. Scandinavian Journal of Forest Research 24 (3), $235-246$.

Favillier, A., Lopez-Saez, J., Corona, C., Trappmann, D., Toe, D., Stoffel, M., Rovéra, G., Berger, F., 2015. Potential of two submontane broadleaved species (acer opalus, quercus pubescens) to reveal spatiotemporal patterns of rockfall activity. Geomorphology $246,35-47$.

Fuhr, M., Bourrier, F., Cordonnier, T., 2015. Protection against rockfall along a maturity gradient in mountain forests. Forest Ecology and Management 354, 224-231.

Gini, C., 1921. Measurement of inequality of incomes. The Economic Journal 31 (121), 124-126.

Gray Stirling, B. W., 2001. Empirical relationships between species richness, evenness, and proportional diversity. The American Naturalist 158 (3), 286-299.

Gsteiger, P., 1993. Steinschlagschutzwald. ein beitrag zur abgrenzung, beurteilung und bewirtschaftung. Schweizerische Zeitschrift für Forstwesen $144,115-132$

Götmark, F., Kiffer, C., 2014. Regeneration of oaks (quercus robur/q. petraea) and three other tree species during long-term succession after catastrophic disturbance (windthrow). Plant Ecology 215 (9), 1067-1080. 
Hollander, M., Wolfe, D. A., Chicken, E., 2013. Nonparametric statistical methods. John Wiley \& Sons.

Jacob Weiner, O. T. S., 1984. The meaning and measurement of size hierarchies in plant populations. Oecologia 61 (3), $334-336$.

Jancke, O., Dorren, L. K., Berger, F., Fuhr, M., Köhl, M., 2009. Implications of coppice stand characteristics on the rockfall protection function. Forest Ecology and Management 259 (1), $124-131$.

Kaufman, L., Rousseeuw, P. J., 1990. Partitioning Around Medoids (Program PAM). John Wiley and Sons, Inc., Hoboken, NJ, USA, Ch. 2, pp. 68-125.

Kunstler, G., Lavergne, S., Courbaud, B., Thuiller, W., Vieilledent, G., Zimmermann, N. E., Kattge, J., Coomes, D. A., 2012. Competitive interactions between forest trees are driven by species' trait hierarchy, not phylogenetic or functional similarity: implications for forest community assembly. Ecology Letters 15 (8), 831-840.

Mansuy, N., Thiffault, E., Paré, D., Bernier, P., Guindon, L., Villemaire, P., Poirier, V., Beaudoin, A., 2014. Digital mapping of soil properties in canadian managed forests at $250 \mathrm{~m}$ of resolution using the k-nearest neighbor method. Geoderma 235-236, $59-73$.

Maringer, J., Ascoli, D., Dorren, L. K. A., Bebi, P., Conedera, M., 2016. Temporal trends in the protective capacity of burnt beech forests (fagus sylvatica 1.) against rockfall. European Journal of Forest Research, 1-17.

Monnet, J.-M., Bourrier, F., Dupire, S., Berger, F., 2016. Suitability of airborne laser scanning for the assessment of forest protection effect against rockfall. Landslides, 1-12.

Morin, X., Fahse, L., Scherer-Lorenzen, M., Bugmann, H., 2011. Tree species richness promotes productivity in temperate forests through strong complementarity between species. Ecology Letters 14 (12), 1211-1219.

Notaro, S., Paletto, A., 2012. The economic valuation of natural hazards in mountain forests: an approach based on the replacement cost method. Journal of Forest Economics 18 (4), 318-328.

Pielou, E., 1966. The measurement of diversity in different types of biological collections. Journal of Theoretical Biology $13,131-144$.

Radtke, A., Toe, D., Berger, F., Zerbe, S., Bourrier, F., 2014. Managing coppice forests for rockfall protection: lessons from modeling. Annals of Forest Science 71 (4), 485-494.

Rammer, W., Brauner, M., Ruprecht, H., Lexer, M., 2015. Evaluating the effects of forest management on rockfall protection and timber production at slope scale. Scandinavian Journal of Forest Research 30 (8), 719-731.

Reynolds, A. P., Richards, G., Iglesia, B., Rayward-Smith, V. J., 2006. Clustering rules: A comparison of partitioning and hierarchical clustering algorithms. Journal of Mathematical Modelling and Algorithms 5 (4), 475-504.

Robert, N., Vidal, C., Colin, A., Jean-Christophe, H., Hamza, N., Cluzeau, C., 2010. National forest inventories reports : France. In: Tomppo, E., Gschwantner, T., Lawrence, M., McRoberts, R. E. (Eds.), National Forest Inventories—Pathways for Common Reporting. Springer, pp. 207-221.

Rohner, B., Bigler, C., Wunder, J., Brang, P., Bugmann, H., 2012. Fifty years of natural succession in swiss forest reserves: changes in stand structure and mortality rates of oak and beech. Journal of Vegetation Science 23 (5), 892-905.

Stoffel, M., Wehrli, A., Kühne, R., Dorren, L. K. A., Perret, S., Kienholz, H., 2006. Assessing the protective effect of mountain forests against rockfall using a 3d simulation model. Forest Ecology and Management 225 (1-3), 113-122.

Straub, D., Schubert, M., 2008. Modeling and managing uncertainties in rock-fall hazards. Georisk: Assessment and Management of Risk for Engineered Systems and Geohazards 2 (1), 1-15.

Tibshirani, R., Walther, G., Hastie, T., 2001. Estimating the number of clusters in a data set via the gap statistic. Journal of the Royal Statistical Society: Series B (Statistical Methodology) 63 (2), 411-423.

Toe, D., 2016. Characterisation of the protection function of coppice stands against rockfall hazard. Ph.D. thesis, Université Grenoble Alpes, Grenoble, France.

Toe, D., Berger, F., 2015. Regional Mapping of Forest with a Protection Function Against Rockfall. In: Lollino, G., Giordan, D., Crosta, G. B., Corominas, J., Azzam, R., Wasowski, J., Sciarra, N. (Eds.), Engineering Geology for Society and Territory. Vol. 2. Springer International Publishing, Cham, pp. 1957-1959.

Trappmann, D., Stoffel, M., 2013. Counting scars on tree stems to assess rockfall hazards: A low effort approach, but how reliable? Geomorphology $180-181,180-186$.

Trappmann, D., Stoffel, M., Corona, C., 2014. Achieving a more realistic assessment of rockfall hazards by coupling three-dimensional process models and field-based tree-ring data. Earth Surface Processes and Landforms 39 (14), 1866-1875.

Turner, W. R., Brandon, K., Brooks, T. M., Costanza, R., Fonseca, G. A. B. d., Portela, R., 2007. Global Conservation of Biodiversity and Ecosystem Services. BioScience 57 (10), 868-873.

Vilà, M., Vayreda, J., Comas, L., Ibáñez, J. J., Mata, T., Obón, B., 2007. Species richness and wood production: a positive association in mediterranean forests. Ecology Letters 10 (3), 241-250.

Wasser, B., Frehner, M., 1996. Minimale Pflegesmassnahmen für Wälder mit Schutzfunktion. Wegleitung. Bundesamt für Umwelt, Wald und Landschaft (BUWAL), Bern.

Wilcoxon, F., 1945. Individual comparisons by ranking methods. Biometrics bulletin 1 (6), 80-83.

\section{Appendix A}

See Fig. A.1 and Fig. A.2. 

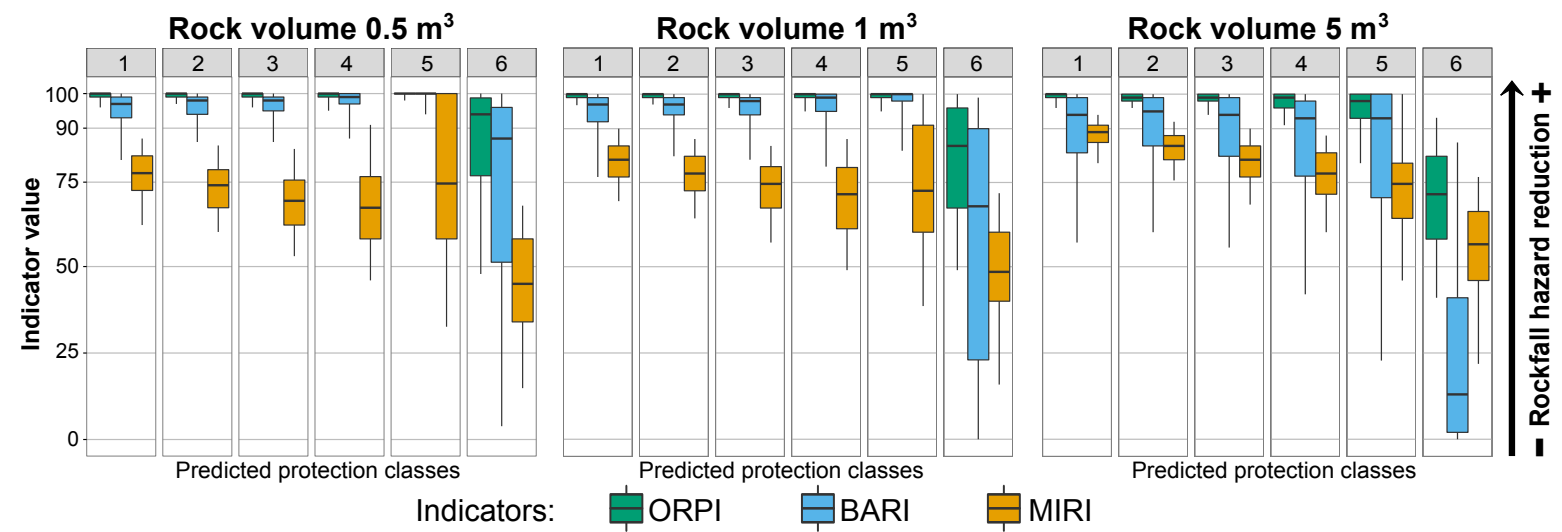

Figure A.1: Distribution of the values of the three indicators according to the six classes of protection. Indicators values shown for classes 1 to 5 correspond to the values observed at $L=110,190320,600$ and $2100 \mathrm{~m}$ respectively. For the protection class $6, O R P I \geqslant 99$ is never reached on the range of forest lengths tested, the indicators values are thus returned for $L=2100 \mathrm{~m}$ which corresponds to the maximum length tested.
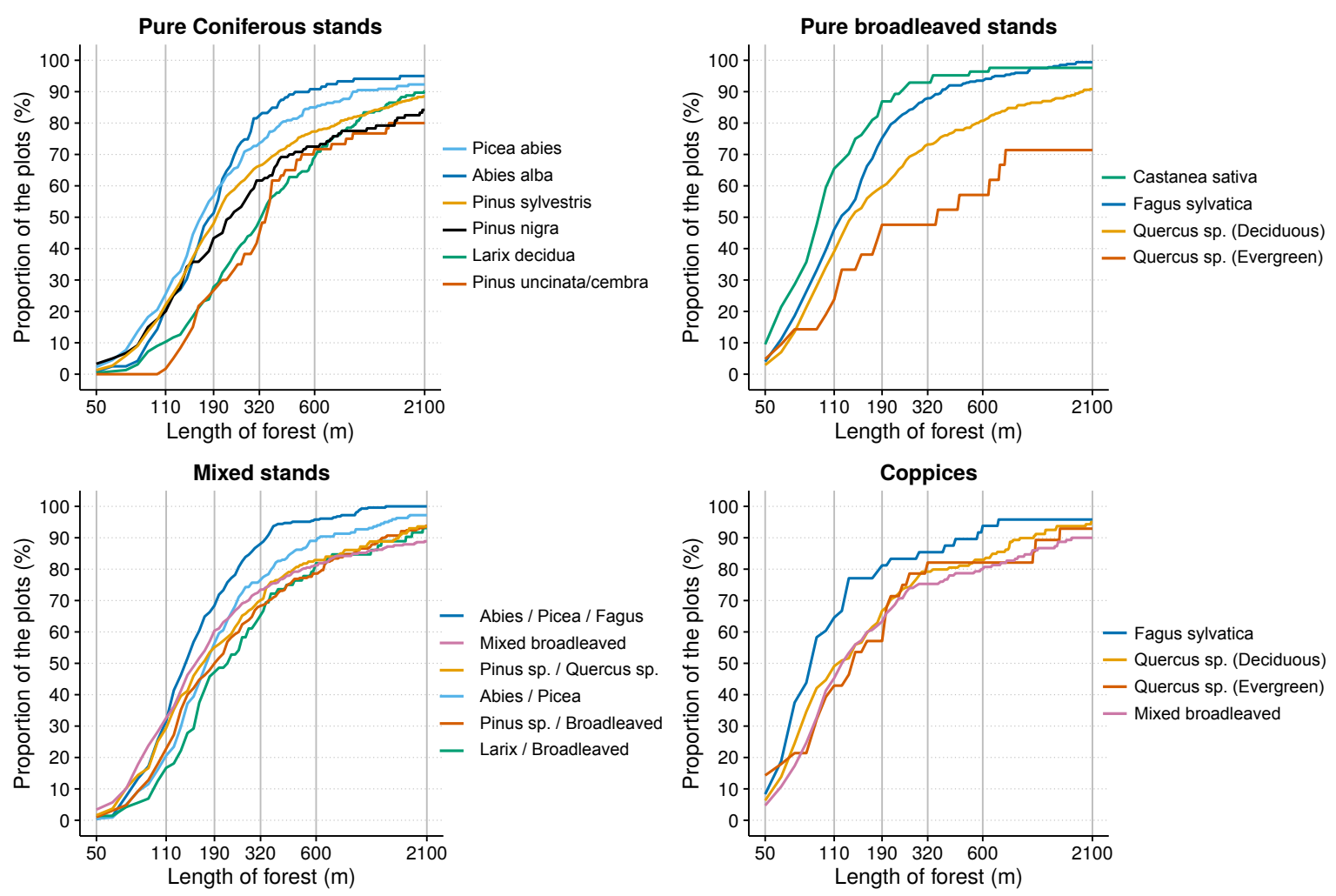

Figure A.2: Proportion of NFI plots by forest type where $\operatorname{ORPI}(x) \geq 99$ for a length of forest $x \in[50-2100] \mathrm{m}$ and a rock volume of $1 \mathrm{~m}^{3}$. 